\title{
A GESTÃO DA DIVERSIDADE E A INCLUSÃO DIGITAL NO ESPAÇO EDUCACIONAL
}

\author{
DIVERSITY MANAGEMENT AND DIGITAL INCLUSION IN THE EDUCATIONAL \\ SPACE
}

José Maria Maciel Lima ${ }^{1}$

RESUMO: O presente estudo se caracteriza como uma pesquisa bibliográfica, pautada em uma abordagem de cunho qualitativa, com dados e informações obtidas através de artigos científicos, disponíveis na internet. $O$ estudo tem como principais objetivos compreender a importância da valorização da diversidade e da redução da desigualdade no cenário educacional; almejando entender os desafios da diversidade especialmente no espaço escolar; refletindo sobre os desafios da gestão escolar, ponderando a importância da gestão democrática para a efetivação de ações afirmativas sobre a diversidade no âmbito educacional. Neste sentido, procura-se abordar os temas a seguir, propostos ao longo desta pesquisa, considerando os seguintes tópicos. De início, aborda-se a gestão da diversidade, no âmbito educacional, dando ênfase a importância de uma gestão eficiente, no combate às desigualdades, com o objetivo de incluir os alunos e oferecer oportunidades de acesso iguais para todos. A seção seguinte, trata-se de abordar os desafios da diversidade e as novas tecnologias, na atualidade. Este tópico traz a luz discussões que enfatizam a importância da democratização da informação para a formação integral do estudante estigmatizado e excluído do mundo digital, na sociedade do século XXI. O terceiro tópico enfatiza a importância da gestão escolar para integração e acesso da diversidade às novas tecnologias da informação e comunicação. No decorrer da pesquisa, foi possível constatar que os desafios da diversidade, no âmbito educacional, estão longe de ser superados, completamente. Mas, através de projetos e propostas pedagógicas afirmativas de combate às desigualdades sociais, no espaço escolar, pode-se amenizar os impactos causados pelas injustiças, principalmente a exclusão digital, e iniciar um processo de inclusão de forma justa, objetivando a oferta de oportunidades iguais para todos.

Palavras-chave: Diversidade. Inclusão digital. Educação. Tecnologia. Escola.

\footnotetext{
${ }^{I}$ Mestrando em Tecnologias Emergentes em Educação - MUST University - Florida - USA. Professor da rede Municipal e Estadual de ensino do Município de Curuá - Pará - Licenciado Pleno em Letras/Português - UFPA, Letras/Espanhol - UNIUBE, Letras/Inglês - UFOPA, Formação de Professores de Filosofia (Licenciatura) - FPA, Licenciado Pleno em Filosofia - FAMOSP. Especialista em Metodologia do ensino de Filosofia e Sociologia - UNIASSELVI, Especialista em Ensino de Língua Espanhola - UNICAM, Especialista em Educação Especial Inclusiva e Neuropsicopedagogia - Faculdade Futura, Especialista em Metodologia de Ensino de Língua Portuguesa, Literatura e Língua Inglesa FAVENI e Especialista em Língua Portuguesa e Literatura Brasileira - FAVENI.. Email: zezinho.curua@gmail.com.
} 
ABSTRACT: The present study is characterized as a bibliographic research, based on a qualitative approach, with data and information obtained through scientific articles, available on the internet. The study's main objectives are to understand the importance of valuing diversity and reducing inequality in the educational scenario; aiming to understand the challenges of diversity especially in the school space; reflecting on the challenges of school management, pondering the importance of democratic management for the effectiveness of affirmative actions on diversity in the educational scope. In this sense, we seek to address the following themes, proposed throughout this research, considering the following topics. Initially, diversity management is addressed in the educational field, emphasizing the importance of efficient management, in the fight against inequalities, with the objective of including students and offering equal access opportunities for all. The next section deals with addressing the challenges of diversity and new technologies today. This topic brings to light discussions that emphasize the importance of the democratization of information for the integral formation of the stigmatized and excluded student of the digital world, in the society of the 2ist century. The third topic emphasizes the importance of school management for the integration and access of diversity to new information and communication technologies. During the research, it was possible to verify that the challenges of diversity, in the educational scope, are far from being completely overcome. But, through affirmative pedagogical projects and proposals to combat social inequalities, in the school space, the impacts caused by injustices, especially digital exclusion, can be mitigated and a process of inclusion can be started in a fair way, aiming at the offer of equal opportunities for all.

Keywords: Diversity. Digital inclusion. Education. Technology. School.

\section{INTRODUÇÃO}

As práticas didático-metodológicas tradicionais estão longe de desaparecer das ações pedagógicas diárias de sala de aula. Evidências de experiências docentes nos revelam que mesmo aceitando e inserindo na prática docente o novo modelo curricular proposto pela BNCC e imposto pelo advento do avanço das novas tecnologias e pela Pandemia do Corona vírus, um sistema, uma correte filosófica ou epistemológica, não suplanta o paradigma anterior, completamente. Além disso, muitos gestores e professores ainda não têm ciência ou não querem aceitar o novo paradigma emergente, que sugere a isenção das novas tecnologias digitais na sala de aula para o uso pedagógico, ambicionando melhorar a qualidade da educação, democratizar o acesso à 

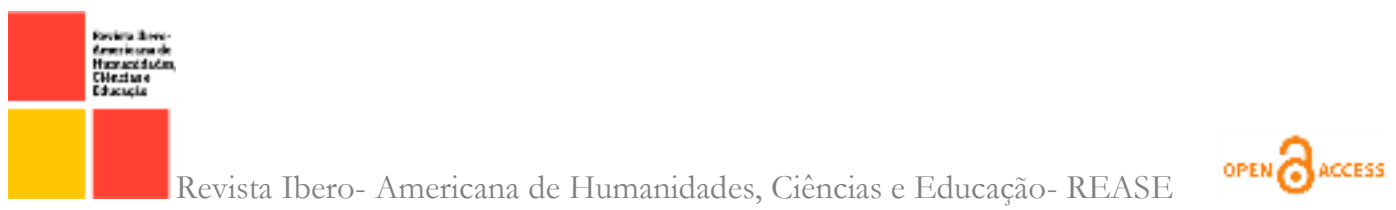

informação, em um processo de inclusão digital, que deve ser iniciado pela instituição escolar.

Neste cenário bastante disruptivo, os projetos de inovação tecnológica podem derrubar as barreiras impostas pelo ensino tradicionalista, propostas pedagógicas que imprimem a desigualdade, que impedem a escola e sociedade de acompanhar o desenvolvimento e o avanço das tecnologias digitais e melhorar a qualidade da educação. De acordo com experiências de países desenvolvidos como a Finlândia, que acreditam no potencial transformador da educação, a aprendizagem baseado em projetos de inovação tecnológica, que consideram a diversidade um processo natural de todas as sociedades humanas, tem se mostrado eficiente em promover uma aprendizagem significativa para a vida do educando, contribuindo para a construção de seu projeto de vida, formando sujeitos autônomos para enfrentar as demandas e os desafios impostos pela sociedade do século XXI.

Nesta perspectiva, este artigo apresenta uma pesquisa bibliográfica de cunho qualitativa, que tem como objetivo estudar para compreender a relevância da valorização da diversidade para reduzir a desigualdade no cenário escolar; entender os desafios da diversidade, especialmente, no campo educacional; discutir os desafios da gestão escolar enfatizando a importância da gestão democrática para a efetivação de ações afirmativas voltadas para a efetivação e valorização da diversidade na escola.

Para tanto, o presente estudo está estruturado em três seções, sendo que a primeira, denominada de a gestão da diversidade no âmbito educacional, aborda a diversidade no espaço educacional, trazendo para a luz das reflexões um estudo que defende a diversidade na escola, pondo em cheque a questão da desigualdade de acesso à educação e a informação. Prosseguindo as discussões, discute-se sobre os desafios da diversidade e as novas tecnologias, na atualidade, enfatizando os desafios da inclusão digital, diante de um cenário tecnológico, inovador, plural e desigual. Na seção seguinte, traz-se uma abordagem ponderando a gestão escolar, as tecnologias e os desafios da diversidade, no âmbito da escola, com foco em propostas de inclusão digital, considerando e valorizado a diversidade no espaço educacional. 


\section{A GESTÃO DA DIVERSIDADE NO ESPAÇO EDUCACIONAL}

Em consulta à diversas fontes, constatou-se que a diversidade pode ser definida como a relação que se estabelece entre indivíduos que apresentam identidades diferentes e convivem no mesmo espaço social. Diante isso, é necessário estabelecer regras que normatizem as diferenças no nível social, organizacional e grupal, objetivando amenizar as desigualdades sociais. Sendo assim, sabe-se da amplitude do tema, porém, propõe-se, nesta seção, refletir sobre a diversidade no âmbito educacional. Mas, primeiramente, far-se-á um breve regaste histórico da diversidade, de um modo geral.

Do ponto de vista político e jurídico, a necessidade de se pensar em um amparo para proteger a diversidade humana advém do pós-segunda-guerra mundial com a Declaração Universal dos Direitos Humanos de 1948. Parte deste tratado consta na Constituição Federal brasileira de 1988, a qual influenciou a criação de legislações mais específicas e políticas públicas para amparar a diversidade (BRAZ \& PRADO, 2020, p. 62585).

Posterior a esses acontecimentos, a gestão da diversidade emerge com certa intensidade nos Estados Unidos, com a publicação da affirmative action, no final do ano de 1960, que determinou que as empresas que tivessem acordos com o governo avaliassem a diversidade e diversificasse o seu quadro funcional. Anos mais tarde, especificamente, na década de 9o, surgem estudos, ações e políticas mais sólidas sobre a temática, e novas leis são criadas para assegurar, nas empresas, a gestão diversidade nos EUA (BRAZ \& PRADO, 2020).

Desse modo, não há como negar que os estudos e pesquisas aceca do tema diversidade, as atuações jurídicas e políticas foram fundamentais para que as empresas tomassem como norma legal a diversificação do seu quadro funcional. Sendo assim, essas organizações tiveram que planejar, estudar e se adequar às novas exigências do mercado, que começou a se apresentar-se bastante diversificado, vislumbrando e, ao mesmo tempo, mascarando a diversidade de diversas maneiras, como nos dias atuais.

Nas palavras de Carvalho (2012), a partir dos anos 2000, a gestão da diversidade tem sido uma preocupação frequente, não somente das escolas, mas também de empresas privadas que, juntamente, com o governo vem demonstrando interesse no assunto. Sendo assim, o cenário nacional, começa, aos poucos, apropriar-se dos acontecimentos do cenário mundial. 
A Europa, nas últimas décadas, apresenta um grande crescimento na diversificação da força de trabalho, o que ocasionou a publicação de uma série de medidas legais contrárias a discriminação de qualquer ordem, que se estende do assédio à outras formas de opressão, que cause algum tipo de constrangimento ou prejuízos de natureza financeira ou psicossocial ao trabalhador. Sendo mais específico, a discriminação está sempre relacionada à origem étnico/racial, a indivíduos que apresentam necessidades especiais, a idade, a orientação sexual, ao credo ou religião. Face a isso, as organizações empresarias, estão percebendo a necessidade de se adequar as novas demandas da atualidade para gerir, de forma justa, a diversidade no âmbito organizacional (empresarial e educacional).

Em seus postulados, Carvalho (2012), pondera que defender e efetivar a diversidade é assegurar os direitos humanos e as liberdades essenciais, principalmente garantir os direitos aos indivíduos que pertencem a grupos minoritários. Nas palavras da autora, estamos vivendo o apogeu da pluralidade cultural e de identidade. Sendo assim, "o respeito à diversidade vem se tornando um valor, uma condição irrenunciável e inegociável na cena política, adquirindo à primeira vista um status quase natural, inquestionável” (CARVALHO, 2012, p.92).

Assinalando alguns marcos importantes na luta pela diversidade, não se pode deixar de pontuar que a gestão da diversidade caminha junto com a defesa da participação social, que tem ganhado destaque na participação política dos indivíduos, sobretudo, a partir da segunda metade da década de 9o, com a reforma do Estado. A partir disso, a gestão pública, a sociedade civil passou a ter um lugar importante no desenvolvimento de papeis que, antes, eram uma exclusividade do Estado - que mesmo depois dessa conquista para a sociedade, não abdicou de planejar e de definir as políticas públicas, que atende as necessidades da sociedade.

O cenário educacional é contagiado por um espírito de mudança de respeito a diversidade e começa a incorporar as determinações estabelecidas pela nova (naquele momento) Lei de Diretrizes e Bases da Educação Nacional no. 9394/96, promulgada no ano de 1996. Essa lei representa muitas conquistas, principalmente no campo da diversidade, trazendo em seu bojo a proposta da obrigatoriedade de uma gestão escolar 
democrática, cuja a participação de todos os envolvidos no processo de ensino e aprendizagem é fundamental. Anos à frente, as conquistas se ampliam ainda mais.

Nesta perspectiva de mudança, embora o governo detenha o poder de determinar os objetivos, o orçamento, as diretrizes curriculares e os sistemas de avaliação das instituições educacionais, preferiu descentralizar a gestão, proporcionando autonomia financeira, pedagógica e administrativas às instituições de ensino, que a partir de então, passaram a contar com maior participação da comunidade escolar (CARVALHO, 2012).

\begin{abstract}
$\mathrm{Na}$ prática, o que se tem observado é a transferência de competências e responsabilidades para as coletividades locais, o encorajamento das "parcerias" e a adoção de um modelo educativo mais diversificado, com projetos pedagógicos voltados para as expectativas das comunidades e para suas conjunturas sociais específicas. Espera-se que isso resulte em uma ampliação da democracia, já que se procura a adaptação da escola à diversidade da população e à variedade das demandas locais, a ampliação da participação dos atores locais e a gestão periférica da diversidade social (CARVALHO, 2012, p. 96).
\end{abstract}

Nas palavras da autora mencionada acima, as orientações tradicionais que norteiam gestão do trabalho pedagógico são consideradas inadequadas para uma sociedade tão plural com a nossa. Além disso, em tempos tão moderno, exige-se uma gestão da diversidade contemporânea. Dessa forma, há que se ressaltar, que um modelo centralizador, burocrático, autocrático, impositivo, na qual os conhecimentos, conteúdos, as práticas pedagógicas não são adequadas a uma sociedade que se diversifica cada vez mais, serve apenas para excluir os grupos minoritários, portanto um distanciamento das práticas democráticas.

Neste cenário plural, vê-se a necessidade de reconhecer e valorizar a diversidade no ambiente educacional, oferecendo atenção especifica às necessidades de cada estudante através de uma pedagogia que atenda às diferenças de forma individual. Além disso, há de se considerar a participação da comunidade escolar. É de suma importância que todos os agentes envolvidos no processo de ensino e aprendizagem participem das ações da escolar. Além disso, é fundamental o acompanhamento da comunidade escolar para o desenvolvimento de projetos pedagógicos que abordem temas sensíveis, inclusive a diversidade no ambiente escolar.

É neste cenário, em que a sociedade, desembaraçada das restrições e intervenções do Estado, dá ênfase aos mecanismos de mercado e à 
privatização, que os termos como diverso, diferença, individual, local se impuseram como expressão das aspirações sociais. Isso tem levado a um abandono dos ideais de igualdade e universalidade, ou seja, do acesso igualitário à instituição escolar e ao conhecimento que, diga-se de passagem, caracterizou as lutas sociais no interior do século $\mathrm{XX}$ em prol de uma educação pública nacional e democrática (CARVALHO, 2012, p. 96).

Considerando os termos da diversidade como a própria igualdade, é importante salientar que entra em cena diversas maneira de desigualdade, como se a velha bandeira de defesa do direto à educação estivesse obsoleta. Neste caso, evidencia-se que a diversidade não gera igualdade "e que a defesa política da igualdade não implica que as práticas pedagógicas e organizacionais não possam vir a ser diferentes, mas sim que a diferença seja sempre subordinada à missão de universalização dos saberes" (CARVALHO, 2012, p. 97).

Diante disso, percebe-se que a gestão da diversidade, no âmbito educacional está muito além do respeito às diferenças, engloba uma série fatores, que sozinho, o gestor, não conseguiria realizar para assegurar a igualdade a todos os envolvidos no processo de ensino e aprendizagem. Sendo assim, a união da comunidade escolar, de um modo geral, é fundamental para colaborar de forma participativa com a gestão da diversidade na escola, no desenvolvimento (implantação e implementação) de projetos pedagógicos que envolvam o tema. Entre várias ações planejadas em conjunto, está a adesão de políticas públicas voltadas para a diversidade, que embora insuficiente e, às vezes, mascaradas de preconceitos, tem contribuído para amenizar a discriminação e exclusão social dos grupos minoritários em vários setores sociais.

No mais, a participação da comunidade escolar, inspira uma gestão democrática e participativa, mas não se deve esquecer da participação e responsabilidade do Estado, que descentralizou a gestão, mas continua a subfinanciar a educação. Devemos compreender que a descentralização da gestão não pode substituir a reponsabilidade do Estado. Portanto, já se avançou bastante em termos de conquistas, no campo da diversidade, mas, ainda, há muito a ser conquistado. Sendo assim, a luta continua... E essa bandeira é nossa: Estado, docentes, gestão administrativa, gestão pedagógica, comunidade escolar, de um modo geral e todos os envolvidos no processo de ensino e aprendizagem. 


\section{OS DESAFIOS DA DIVERSIDADE E AS NOVAS TECNOLOGIAS NA ATUALIDADE}

Os desafios da diversidade perpassam por vários temas de grande relevância para o desenvolvimento e crescimento da sociedade atual. $O$ avanço e o acesso às novas tecnologias em uma sociedade plural/diversa se apresenta como um grande desafio para o governo e sociedade, em um país subdesenvolvido e tão desigual como o Brasil. Em uma breve análise é possível perceber que o acesso às tecnologias e ao mundo digital, ainda é uma realidade da minoria, assim sendo, a exclusão digital permanece imperativa, reforçando ainda mais a desigualdade entre grupos minoritários e estigmatizados socialmente.

Neste sentido, percebe-se que a diversidade se confunde com a desigualdade. Se considerarmos que os grupos minoritários e periféricos sempre foram discriminados e estigmatizados, pondera-se que a diversidade caminha de mãos dadas com a desigualdade. Porém, não há nada de negativo neste sentido, considerando a riqueza cultural e de identidade de um povo diverso, que sofreu influência de várias culturas em seu processo de formação. Talvez, o sentido mais relevante da diversidade esteja nesta informação, a mistura de raças e culturas é um fator positivo para a formação de uma nação. Portanto, não cabe, neste contexto, uma visão etnocêntrica da diversidade cultural, pois não existe cultura pura. Sendo assim, é preciso apreciar o hibridismo cultural. Nesta perspectiva, as culturas devem se equivaler.

A escola deveria ser a porta de entrada para o universo digital, considerando que o mundo está cada vez mais tecnológico, e a instituição escolar é lugar comum de educação formal, que defende ou deveria defender a bandeira da igualdade e da democratização de acesso aos bens culturais e serviços, fazendo valer os diretos iguais para todos. Sendo assim, descriminar é um ato contraditória ao verdadeiro papel da escolar. No entanto, "a educação é um dos domínios onde, por efeito desses factores, as mudanças seriam mais necessárias. Mas é onde parecem mais lentas e contraditórias” (Cardoso, 200I, p.I).

É incontestável que aquela diversidade e a disponibilidade de NTIC, cada vez mais rápidas e globais (internet, rede alargadas de televisão, computadores, programas informáticos, etc), têm influenciado a actuação prática dos 
professores. Contudo parece não terem ainda ocorrido alterações significativas, sugeridas por aquelas mudanças, do quadro ideológico da acção dos professores. Apesar da crescente facilidade no acesso, tratamento e produção de informação através das NTIC, não tem sido fácil o reconhecimento pela escola e pelos professores de que tal processo os coloca cada vez mais longe da centralidade que ocupavam na distribuição da informação. Só muito lentamente têm vindo a emergir novas formas de tratamento do conhecimento escolar capitalizando fontes e processos mediáticos (CARDOSO, 200I, p. I).

$\mathrm{Na}$ atualidade, as tecnologias é a porta de entrada para o mundo do trabalho, para uma formação acadêmica e profissional mais sólida com chances de sucesso. Além disso, os recursos tecnológicos estão presentes diariamente na vida das pessoas, utilizase a tecnologia para realizar uma série de tarefas diárias, se não todas, (permita-me modalizar), mas quase todas. Ressalta-se ainda, que o homem é um ser social, logo, este, não pode está aquém aos acontecimentos e aos avanços sociais, tecnológicos e científicos. Não se pode encarrar a diversidade como um problema, mas sim como um ato natural de todas as civilizações evoluídas e modernas. O problema está em não saber como the dar com esse fator comum a todas as sociedades. Corroborando com essa ideia, Nobre (2021, p.3), assinala que:

A diversidade sempre existiu dentro da sociedade, contudo, por muito tempo ela foi velada e as pessoas eram obrigadas a seguir padrões tradicionais rígidos de um modelo imposto e tido como ideal, como normal. Tudo que estava na contramão desse modelo, era visto como errado e imediatamente negado, mal visto, discriminado e isolado da sociedade.

Apesar das políticas públicas governamentais que objetivam minimizar a exclusão digital, esse tipo de desigualdade ainda é uma realidade da sociedade brasileira, o que tudo indica, está longe de acabar, mas é necessário lutar para assegurar os direitos iguais a todos os povos, principalmente aos que mais sofrem com a discriminação. É necessário um esforço conjunto do governo e da sociedade para alcançar aqueles que estão às margens do alcance digital. Segundo Cardoso (2001), dados do IBGE de 2014, revelam-nos que $50 \%$ da população brasileira possui acesso a rede global de computadores, em suas residências e mais de $80 \%$ dos brasileiros utilizam Smartphone para acessarem a Internet. Comparados a outros períodos, vislumbra-se um avanço de um número significativo de usuários da rede global. Estudos nos revelam que esse avanço se deve a popularização da internet, no século XXI, a necessidade de se utilizar a tecnologia diariamente e a exigência do mercado de trabalho. Vale ressaltar que os 
indivíduos imersos nessa realidade, pouco percebem o quanto estão envolvidos e dependentes das tecnologias (NOBRE, 2021).

Diante disso, pondera-se que a escola deveria ser lugar de inclusão. Mas, no Brasil, apesar do esforço do governo em equipar as escolas com recursos tecnológicos e incluir os alunos, digitalmente, principalmente aqueles que não tem acesso a esses equipamentos em sua residência, o que ocorre, normalmente, é que despois de equipado, o laboratório de informática é trancado e permanece por anos intocável. Situações como essas, são corriqueiras em nossas escolas e embaraçam o desenvolvimento intelectual e cognitivos de nossos alunos, que tem seus direitos tolhidos por gestores que pararam no tempo.

O resultado disso, são: desperdiço do dinheiro público, equipamentos deteriorados pelo tempo, falta de uso e a ausência de manutenção. Neste sentido, percebe-se que para que a inclusão digital seja um fator consumado, principalmente, na escola, é necessário implantar e implementar projetos sólidos de inclusão digital, que atendam, principalmente, às necessidades, da diversidade social. Mas, antes disso, necessita-se que o professor tenha competências e habilidades necessárias para orientar o uso crítico, criativo e colaborativo adequado e proveitoso dos recursos tecnológicos para fins educativos.

\footnotetext{
Para além de competências técnicas para lidar com as NTIC em termos de as inserir no processo curricular, espera-se que os professores desenvolvam perspectivas ideológicas que lhes permitam a análise crítica e reflexiva dos problemas e questões sociais que directa ou indirectamente alimentam aquelas tecnologias; ou seja, de um professor mediador, sistematizador, apoiante de escolhas, capaz de abertura democrática face a diversas perspectivas ideológicas. É uma exigência que vem da necessidade de ter de lidar com a diversidade. Diversidade (e quantidade) de informação, com muitas fontes e através de diversos meios; diversidade de alunos e suas famílias definidos por saberes, atitudes e crenças muito diversificados (CARDOSO, 20oI., p. 2).
}

Neste cenário, pontua-se que os desafios da diversidade e das novas tecnologias poderiam ser bem mais simples se a escola, realmente, abrisse suas portas para o mundo teológico e encarasse a diversidade com um fator natural e positivo. Mas, quase sempre, não é isso que ocorre. $O$ que se tem assistindo é negação dos direitos aos alunos à inclusão digital. Desse modo, a desigualdade de perpetua ainda mais, os indivíduos que residem em grandes centros urbanos são privilegiados por uma infinidade de recursos 
tecnológicos avançados, enquanto que, aqueles que vivem em lugares distante das grandes cidades são desfavorecidos dessas tecnologias, muitos não possuem, se quer, um aparelho celular, ou porque não há cobertura de telefonia móvel no local, ou por situações socioeconômicas - a Pandemia do novo corona-vírus nos revelou isso muito claramente. Desse modo, talvez, a escola fosse o único lugar onde esses indivíduos, desprivilegiados, tecnologicamente, tivesse acesso aos recursos e aparatos tecnológicos. Sendo assim, conclui-se que a escola deve somar esforços juntamente com o Estado, comunidade escolar, todos agentes envolvidos no processo de ensino e aprendizagem para que juntos, possam elaborar projetos de inclusão digital que atendam a diversidade de alunos que a instituição educacional recebe.

\section{O PAPEL DA GESTÃO ESCOLAR E OS DESAFIOS DA DIVERSIDADE E AS NOVAS TECNOLOGIAS}

O contexto educacional vive momentos de profundas transformações, as tecnologias avançam muito rapidamente e se expandem para todos os setores da sociedade, principalmente para o educacional. Atualmente, pondera-se que não há muita saída para aqueles profissionais da educação que insistem em práticas tradicionalistas de ensino e tentam excluir das práticas pedagógicas as novas tecnologias. Nesta perspectiva, assinala-se que a escola não deve caminhar em contramão ao avanço social, tecnológico e cientifico. Além disso, o aluno não deve viver uma realidade dentro da escola, e fora dela outra. A escola, assim como o que é ensinado nela, deve fazer sentido à vida do educando, as tecnologias estão tão presentes no dia a dia dos estudantes que eles a utilizam para realizar, se não todas, mas quase todas as tarefas da vida diária.

Neste contexto, a diversidade também deve ser refletida, principalmente, porque, na atualidade, o acesso a informação poder ser um fator gerador de descriminação e exclusão, considerando que nem todos tem acesso às informações que circulam na rede global. Outro fator que impede o acesso à rede mundial de computadores está relacionado ao analfabetismo digital - que pode estar ligado a má gestão da diversidade no cotidiano escolar, e se agravar ainda mais, se a gestão administrativa e pedagógica não for competente o suficiente para elaborar projetos 
pedagógicos, ou até mesmo propostas pedagógicas que objetivem a superação das desigualdades que causam exclusão digital e outros tipos de exclusão.

Neste sentido, é necessário que a gestão escolar seja comprometida com a transformação do ser humano e da sociedade, através de aquisição de competências e habilidades necessárias para superar as barreiras impostas pela desigualdade social, que permeia todos os setores da sociedade, principalmente a escola.

Para isso, é necessário possibilitar à comunidade escolar vivenciar esse processo de inclusão digital por intermédio de situações potencialmente pedagógicas e catalisadoras, que garantam a apropriação e a sustentabilidade dessas tecnologias e, principalmente, que permitam a autonomia da escola na gestão desse processo. $O$ primeiro passo é a capacitação dos profissionais da educação, inclusive por meio de estratégias metodológicas alternativas, como a Educação a Distância - EAD, possíveis através da internet ou TV, que representam uma valiosa oportunidade de formação em serviço e atualização constante a todos (PRATA, 2010, p.I).

Neste processo de formação, é preciso considerar todos os profissionais $\mathrm{da}$ educação, principalmente os envolvidos diretamente como processo de ensino e aprendizagem: professores, gestão administrativa, gestão pedagógica e outros que contribuem, estrategicamente, para promover e melhorar a qualidade da educação. Além disso, o gestor deve ser o condutor desse processo, através de uma gestão democrática e participativa, valorizando e respeitando as diversidades, gerindo o espaço educacional, oportunizado a todos, as mesmas condições de acesso ao conhecimento, independe de fatores étnicos-raciais, origem, deficiência, idade, orientação sexual, crença ou religião. "Os gestores, nada mais são do que educadores que, em dado momento, se tornaram responsáveis pela condução desse processo. Cabe-lhes, portanto, criar as condições necessárias para que ele se efetive" (ALONSO, 2004, p. 7).

Não restam dúvidas de que a melhor forma dos gestores favorecerem a construção de um ambiente saudável e estimulante para os professores é através do trabalho colaborativo e da formação de equipes de trabalho. Situações como essas reduzem as distâncias entre gestores, professores, alunos, funcionários e comunidade, propiciando que todos possam atuar como sujeitos da educação, rompendo com as barreiras criadas pela hierarquia e isso é importante porque o trabalho educativo é produto de uma interação em que onde todos os envolvidos participam e são influenciados de alguma forma. $\mathrm{Na}$ condição de educando ou de educador ambos se modificam. Portanto, o ato educativo é uma ação de via dupla e é com essa ideia em mente que professores e alunos devem se envolver nesse processo (ALONSO, 2004, p.67). 
Pesquisadores como Moran (2015) tem nos revelado que a educação integrada às novas tecnologias para o uso pedagógico, de forma crítica, criativa e colaborativa, temse mostrado eficiente na promoção de uma educação emancipadora, que respeite a diversidade, promovendo a igualdade, cooperando para o crescimento intelectual dos alunos, desenvolvendo habilidades e competências exigidas para viver e atuar na sociedade do século XXI, fornecendo autonomia para os indivíduos protagonizarem seus projetos de vida, através de uma formação integral, ocasionada pelo acesso democrático às informações disponíveis na rede mundial de computadores.

\footnotetext{
Dessa forma, a tecnologia na educação pode ser vista como uma ferramenta pedagógica, altamente relevante para criar um ambiente interativo, que proporcione ao aluno, investigar, levantar hipóteses, pesquisar, criar e, assim, construir seu próprio conhecimento, formando o pensamento crítico e reflexivo (QUEIROZ et al., s/d, p. o5).
}

Neste contexto disruptivo e fértil, vislumbra-se a necessidade de inserção das novas tecnologias na educação. Durante estudos e observações sobre os temas diversidade e tecnologia, constatou-se que não será o aluno a levar os recursos tecnológicos para as salas aulas e fazer o uso pedagógico adequado, de forma democrática, crítica, criativa e colaborativa, considerando a diversidade. Certamente, essa ação deverá ser impulsionada pela gestão administrativa, juntamente com a coordenação pedagógica e de tecnologias e aceita pelos professores como aliada na promoção de ações pedagógicas que considere a diversidade um fator natural e positivo para a formação de uma sociedade mais justa e igualitária. Além disso, é preciso considerar que os alunos da atualidade são nativos digitais, e consequentemente, a maioria, utiliza, diariamente, os recursos tecnológicos para realizar uma série de tarefas no seu dia adia.

Neste cenário inconstante, o gestor escolar tem um grande desafio, conduzir sua equipe docente e técnica/pedagógica em direção à adaptação e aceitação da cultura digital, que emerge a todo vapor no âmbito social. De acordo com Queiroz et al., (s/d), os gestores precisam participar do processo de inclusão digital.

Sabe-se que estas questões perpassam, não apenas por formação continuada de professores, mas, também, pela necessidade de participação do gestor em cursos de qualificação, para que este possa incentivar a presença da tecnologia no contexto administrativo e pedagógico na escola. Assim, tendo a figura do 
gestor educacional como importante no processo de ensino-aprendizagem, por ser ele um articulador que compartilha tarefas e valoriza a participação de todos os atores sociais, deve contribuir para uma reflexão sobre a relação entre teoria e prática e proporcionar a experimentação de novas alternativas pedagógicas, ressignificando as práticas tradicionais, promovendo as transformações necessárias, permitindo a utilização e criação de variadas e diferentes experiências de aprendizagens (QUEIROZ et al.,n.d., p. 6-7).

Nas palavras de Queiroz et al., (s/d), o mundo está em constante transformações, vivemos em outra época e as escolas precisam estar atentas a essas questões. Sendo assim, o gestor educacional desempenha um papel fundamental de sugerir novas maneiras de conduzir as ações pedagógicas, no âmbito escolar, para aproximar a escola da realidade tecnológica que vivemos. Nesta perspectiva, o gestor escolar deve encorajar ações e projetos de tecnologias com propostas inovadoras que promovam a diversidade e favoreça a aprendizagem criativa, crítica e colaborativa.

Portanto, no contexto das mudanças que invadiram o cenário educacional, e, consequentemente, a gestão educacional, a formação continuada ganha progressiva importância, como sinal de que o aprendizado deve assumir caráter permanente e dinâmico na vida dos profissionais de qualquer organização humana (QUEIROZ et al., s/d., p. 7).

No dizer de Almeida e Rubim (2004), as tecnologias isoladas, não podem causar mudanças. Sendo assim, sua inserção no ambiente escolar exige a formação de todos os envolvidos no processo de ensino e aprendizagem, para que desenvolvam competências necessárias para verificar as necessidades das instituições de ensino, referente ao uso das tecnologias digitais na educação. Esse processo de formação sustenta o papel da direção na gestão das tecnologias digitais e na investigação de melhores condições que auxiliem na articulação e no uso administrativo e pedagógico das novas tecnologias digitais, no âmbito educacional, voltadas para todos.

Destarte, os gestores educacionais precisam articular com diversos segmentos da comunidade na qual a escola está inserida para unir forças e apoiar propostas inovadoras de inserção das tecnologias na escola, nos diversos setores administrativos e pedagógicos, para contemplar a diversidade e reduzia as desigualdades sociais. Além disso, é necessário oferecer condições para que os profissionais envolvidos no processo de ensino e aprendizagem possam prosseguir em sua carreira acadêmica se qualificando, seja em cursos de formação continuada ou em cursos de pós-graduação. Certamente, uma formação eficiente pode fazer a diferença, contribuindo de maneira significativa 
para transformar o ambiente escolar em um lugar articulador e produtor de informações e conhecimentos construídos e compartilhados coletivamente, de forma democrática.

\section{CONSIDERAÇÕES FINAIS}

As melhores práticas da gestão da diversidade nos espaços educacionais devem promover, de maneira colaborativa, o desenvolvimento de competências digitais nos professores e habilidades tecnológicas para serem aplicadas ao processo de ensino e aprendizagem dos alunos, baseada em projetos e propostas pedagógicas que objetivem a inclusão digital, a redução da desigualdade e a democratização da informação.

Diante disso, esse processo deve iniciar com o planejamento e implementação de projetos e propostas pedagógicas bem elaboradas, partindo, primeiramente, da oferta de formação continuada aos docentes, considerando que, em um cenário em constante mudança, cujo o acesso e o domínio das tecnologias ainda é, quase que, restrito a um público pertencente a geração de nativos digitais, muitos professores não desenvolveram habilidades e competências para o letramento digital, que oriente o uso pedagógico, de forma crítica, criativa e colaborativa desse recursos na educação, que contribua para a democratização da informação, a redução da desigualdade social, colaborando para a inclusão digital, respeitando as diferenças.

A escola enquanto uma instituição democrática deve ser a principal instituição a incentivar a democratização da informação e a divulgação do conhecimento. Nesta perspectiva, considerando que estamos na era da informação, a maneira mais democrática e acessível ao conhecimento é através dos recursos tecnológicos. Tendo em vista que não cabe mais nos dias atuais, o simples repasse de conteúdo na escola, através de aulas monótonas, cujo o professor fala e os alunos enfileirados devem internalizar as informações, para resolver uma prova no final do período letivo. Esse modelo de ensino está ultrapassado e não condiz com a realidade atual, principalmente, porque, as informações repassadas pelo professor em sala de aula através de repetição, podem ser acessadas na rede muito facilmente, num curto período de tempo.

Desse modo, a inserção e a democratização dos recursos tecnológicos na escola, devem almejar, principalmente, o respeito as diferenças, de uma forma que promova 
um ensino criativo, inovador, colaborativo e crítico, capaz de potencializar o pleno desenvolvimento dos alunos, na perspectiva de viabilizar seu projeto de vida, para as demandas do século XXI.

\section{REFERÊNCIAS BIBLIOGRÁFICAS}

ALMEIDA, M. E. B. \& RUBIM, L. C. B. O papel da gestão escolar na incorporação das TIC na escola: experiências em construção e redes colaborativas de aprendizagem. Disponível em: http://www.eadconsultoria.com.br/ biblioteca_pdf/textoo4.pdf. Acessado em: 02 mai. 2021.

QUEIROZ, C. J. P. et al. O papel do gestor educacional no uso das tecnologias da informação e comunicação: possibilidades e limites. Disponível em: https://eventos.set.edu.br/enfope/article/viewFile/2072/696. Acessado em: 02 mai. 202I.

RAMOS, M. N. PUCPR + FTD. Novo Ensino Médio: Intencionalidade no planejamento por uma educação integradora. Disponível em: https://www.youtube.com/watch?v=QarAV2FaS9c\&feature=youtu.be. Acessado em: 02 fev. 202I.

CARVALHO, E. J. G. Diversidade cultural e gestão escolar: alguns pontos para reflexão. Rev. Teoria e Prática da Educação, v. 15, n. 2, p. 85-10o, maio./ago. 2012. Disponível em: https://periodicos.uem.br /TeorPratEduc/article/view/20181/10527. Acessado em: 26 nov. 2021.

CARDOSO, C. Os desafios da diversidade e das novas tecnologias. Disponível em: http://www.apagina.pt $/$ ?aba $=7 \& c a t=107 \& d o c=8565 \& \mathrm{mi} \mathrm{d}=2$. Acessado em: 26 nov. 2021.

NOBRE, V. N. N. Gestão da diversidade $e$ as novas tecnologias: um cenário desafiador. Atena Editora 2021. Disponível em: https://sistema.atenaeditora.com.br/index.php/admin/api/artigoPDF/45037. Acessado em: 26 nov. 2021.

PRATA, C. L. Gestão escolar $e$ as tecnologias. Disponível em: http://www.virtual.ufc.br/cursouca/modulo_3b_gestores/tema_05/anexos/anexo_5_tic s_na_gestao_escolar2oro_CarmemPrata.pdf. Acesso em: 26 nov. 2021.

BRAZ, M. M. A. \& Prado, A. I. S. Gestão da diversidade no cotidiano escolar. Curitiba, v. 6, n. 8, p. 62584-62607 aug. 2020. ISSN 2525-876r. Disponível em: https://www.brazilianjournals.com/index.php/BRJD/article/view/15679. Acessado em: 29 nov. 2021.

ALONSO, M. Gestão escolar: revendo conceitos: formação de gestores escolares para o uso das tecnologias da informação e comunicação. Disponível em: 
https://docplayer.com.br/6276993-Gestao-escolar-revendo-conceitos.html. Acessado em: 30 nov. 2021.

Mora, J. Educação híbrida: um conceito chave para a educação, hoje. Disponível em: http://www2.eca.usp.br/moran/wpcontent/uploads/2021/or/educa\% $\mathrm{C}_{3} \% \mathrm{~A}_{7 \%} \mathrm{C}_{3} \% \mathrm{~A}_{30}$ _h\%C3\%ADbrida.pdf. Acessado em: 29 jan. 2022. 